\title{
El Urco en Galicia y Asturias: análisis y caracterización
}

\section{The Urco in Galicia and Asturias: analysis and characterisation}

\author{
Aitor Freán CAMPo \\ (Universidade de Santiago de Compostela) \\ ORCID: 0000-0001-5792-5504 \\ aitor.frean.campo@gmail.com
}

\begin{abstract}
It is proposed an exhaustive analysis of Urco in Galicia and Asturias. For this purpose, it is based on information recorded in different works and the search of press articles from the $19^{\text {th }}$ century to the present. Also, it is studied traditions mistakenly associated with Urco and it is reviewed the main interpretations formulated for its origin and meaning. Finally, a new hypothesis is proposed to understand it.
\end{abstract}

Keywords: Asturias, Galicia, Death, Oral Tradition, Popular Imaginary, The Urco
RESUMEN. Se propone una caracterización y un análisis exhaustivo de la figura del Urco en Galicia y Asturias. Para ello se parte de relatos registrados en diferentes obras y del rastreo de artículos de prensa desde el siglo XIX hasta la actualidad. Asimismo, se abordan tradiciones asociadas erróneamente al Urco, se repasan las principales interpretaciones formuladas para su origen y significado y se plantea una nueva hipótesis al respecto.

Palabras-clave: Asturias, Galicia, ima-ginario popular, muerte, tradición oral, Urco

\section{OBJETIVOS Y METODOLOGÍA}

El objetivo fundamental de este artículo es profundizar en el conocimiento de una figura de la cultura popular de tradición oral vinculada al imaginario de la muerte de Galicia y Asturias, como es el Urco. Para ello, se incide en las características físicas, los atributos y las acciones que se enuncian en sus relatos, pero también en aquellos otros en los que se alude a otras creaciones que, en nuestra opinión, representan variaciones geográficas del Urco.

Como consecuencia del mal estado de conservación actual de la tradición, el trabajo se basa, fundamentalmente, en una revisión de las principales fuentes escritas en las que se representa la figura del Urco. De este modo, se hace hincapié en los relatos documentados en diversas recopilaciones y obras bibliográficas (Becoña, 1980; Cabal, 1925; Castro, 2007; Cuba, Reigosa y Miranda, 2006; Fernández, 1993; Filgueira, 1977; Fraguas, 1973; Freán, 2014; Llinares, 1990; Lois, 1887; Mariño, 1995; Suárez, 2001), así como en noticias rastreadas en la numerosa prensa que ha recorrido Galicia y Asturias desde el siglo XIX hasta el día de hoy.

La información obtenida muestra dos realidades bien diferenciadas: en primer lugar, una serie de relatos y creencias que definen unas características y funciones comunes del Urco en Galicia y Asturias y que son enumeradas en el apartado «Análisis y caracterización del Urco en Galicia y Asturias»; por otro lado, diversas alternativas 
a esa tradición común que incorporamos en el apartado «Otras representaciones del Urco» al considerar que se trata de una información que puede ser relevante para nuevas investigaciones y también para comprender ciertas desviaciones con las que se asocia al Urco en la actualidad como, por ejemplo, el personaje que protagoniza los carnavales de Pontevedra.

El lector, a buen seguro, ha de encontrar multitud de similitudes entre el Urco y otras tradiciones situadas en diferentes geografías y cronologías, pero esta investigación se ciñe a los actuales territorios de Galicia y Asturias. Esta realidad se debe a la singularidad de una tradición que, como se verá más adelante, erige al Urco como un ser único, carente de paralelismos exactos en cuanto a su origen y significado. Por este motivo, en este estudio se habla siempre del Urco como manifestación de origen gallego, debido a las diferencias que, desde nuestro punto de vista, sitúan al Huerco asturiano como figura independiente del Urco gallego. Así, aunque ambas figuras comparten la capacidad de augurar la inminencia de la muerte de una determinada persona, tanto su figuración como sus acciones son distintas. Por ello, en este trabajo solo se emplean para el análisis del Urco las referencias asturianas que hacen alusión a esta manifestación, mientras que se ignoran aquellas otras que inciden en la figura del Huerco, entendida como sombra o apariencia de la persona que va a fallecer.

Finalmente, pero no por ello menos importante, otra premisa que se busca con este artículo es divulgar, rescatar del olvido y reivindicar la importancia del Urco para comprender mejor las creencias y mentalidades de la sociedad que en su día dio voz a los sucesos que protagonizaba, pero también de la que en la actualidad los ignora y de aquella que en el pasado dio sentido a su existencia.

\section{ANÁLISIS Y CARACTERIZACIÓN DEL URCO EN GALICIA y Asturias}

Urco, huerco, can do mar, can do urco, os cans, perro negro o perro blanco constituyen diferentes denominaciones de una figura que, aunque se constata en territorios del interior, se erige como una criatura de naturaleza marítima y estrechamente vinculada con el imaginario de la muerte.

Su manifestación más común es aquella en la que se presenta como un perro negro de tamaño colosal y aspecto terrorífico. Son habituales también las descripciones que señalan la posesión de cuernos, ojos fosforescentes, atemorizantes e hipnóticos, unas orejas extremadamente largas para la fisionomía propia de un cánido y la presencia de unas gruesas cadenas alrededor de su cuerpo. Además, la tradición le dota de inmortalidad y sitúa su lugar de residencia en el Borrón o país borroso, un espacio lleno de niebla, perteneciente al Más Allá, ubicado bajo el mar y próximo al infierno, a pesar de que hay quien tiene afinada una localización más precisa a orillas del río Lérez (Pontevedra) (véase Rabanal, 1962).

Cuando el Urco decide salir de sus dominios lo hace con nocturnidad, en las medianoches de plenilunio, abandonando el agua del mar y haciéndose acompañar por sendas y caminos de los perros que duermen fuera de su hogar en la parroquia en la que decide hacer acto de presencia. Hay quien dice que su tamaño se va incrementando una vez abandona el agua, pero su apariencia es siempre temible.

Con su salida del mar, el Urco es capaz de anunciar la muerte de la persona que siente su presencia a través de ruidos, aullidos o lamentos propios de los perros, pero también de la forma en la que lo harían otros animales de mal agüero (lechuzas, urracas, cuervos, zorras, cabras, así como ovejas, gallinas, gallos o terneras, cuando lo hacen a 
deshora). La manera en la que señala la inminencia de la muerte en una determinada vivienda es haciéndose ver ante la persona que la va a sufrir o ante aquella otra que, de alguna manera, está relacionada con esta. Otra forma de presagiar la muerte consiste en interrumpir su trayecto para detenerse delante de la casa del futuro fallecido, bien resoplando o aullando ante su puerta ${ }^{1}$, o bien haciendo correr a los perros negros que lo acompañan tres veces alrededor de la casa.

Normalmente, su recorrido se ciñe a los límites de una determinada parroquia y en el mismo cobran protagonismo elementos de especial relevancia en el imaginario de la muerte: las encrucijadas, los cruceiros, los petos de ánimas y los cementerios. Se trata, pues, de una lógica semejante a la presente, por ejemplo, en las procesiones protagonizadas por la Compaña y sus múltiples variantes (véase Lisón, 1998), pero con la diferencia de que el Urco, una vez finaliza su trayecto, lo desanda para regresar al mar antes del amanecer y bajo la atenta mirada de los perros que lo siguieron en la noche.

Esta es la caracterización más extendida del Urco, aunque, como siempre ocurre en la literatura de tradición oral, las variantes geográficas de esta figura son también destacables. Algunas introducen alteraciones físicas de poca entidad, como aquellas que caracterizan al Urco como un perro blanco, un simple perro común o un grupo de ellos, pero con funciones y atributos análogos a los señalados para el ejemplar negro. Un relato del Urco en forma de perro blanco es el testimoniado por Cabal en territorio asturiano:

Y acontece con frecuencia en los rincones de la Asturias de hoy, que despierta un labriego por la noche, advierte una radiosa claridad, y se dice con asombro:

¡Caramba, si ya es de día!... ¿Cómo me habré dormido hasta tan tarde?

Y va a llamar al vecino, y se ponen entrambos a segar. A poco, ven un perro que se acerca: un perro grande, blanco, silencioso, que los mira con dulzura y sigue su labor con interés. Y ellos forman montones con la hierba, sin ocuparse del perro, y se limpian el sudor que les cae por la cara, como si trabajaran sin descanso bajo el sol del mediodía... Y de pronto sale el sol... Los labriegos se detienen, se contemplan y dicen:

¡La claridad que veíamos era la de la luna!...

Y en efecto, era la de la luna, clara y llena; era la de una luna misteriosa, que llamaban el espacio de fulgores. Y uno de los labriegos dice aún:

¿Mas la hierba cortada, dónde está?...

No se sabe dónde está, puesto que el campo permanece intacto, y no hay en él una brizna separada por la hoz. Y el labriego pregunta finalmente:

¿Pero, y el perro?... ¿Adónde se fue el perro...?

El perro ya no está allí; ha desaparecido ante sus ojos, como si se hubiera convertido en aire... Y ya saben entonces los labriegos lo que les compete hacer: prepararse a morir como cristianos, poniéndose bien con Dios (Cabal, 1925: 55-56).

Con respecto al Urco que se manifiesta con apariencia de perro vulgar, la narración registrada por Lisón en la zona de Muros (A Coruña) constituye un buen ejemplo:

¡Non era por min, home, non era por min! Pero non era por ti ¿o que? O can que ouveaba, home; había un can ouveando aquí había unha morea de días e eu como tiña

\footnotetext{
${ }^{1}$ Hoy en día aún perviven dichos como O Urco... de cada berro, un defunto (El Urco... de cada grito, un difunto).
} 
infección cría que ouveaba porque ía a morrer eu. Pero foi o Antonio o que morreu esta noite [...] Iso do can lévase hoxe en día aquí (Lisón, 1983: 405)².

En otras ocasiones, en lugar de un único perro, el relato muestra la aparición de un Urco doble, tal como se ha constatado en la localidad asturiana de Bermiegu (Quirós):

[...] Un día cuando fueron a trabajar de noche se presentaron dos perros muy grandes, con unas cadenas atadas a las patas, arrastro, perros como caballos de grandes, enormes. Eso era, a mi parecer, cosa del diablo. Y claro, los perros no les hicieron nada a los trabajadores, pero se pasearon por allí, dieron vueltas junto de la obra, junto de los que escarbaban y tal. Dos perros muy grandes, y aquellos perrones con unas cadenas muy gordas, grandes, atadas a las patas, arrastro. $Y$ entonces los rapaces agarraron, marcharon, y que no volvieron más a trabajar. Y entonces habrían topáu ná si es que eso es cierto, porque si los perros los interrumpieron dejaron aquello allí y dijeron: —iyo allí no vuelvo! - . Y yo no sé, esto viene a ser obra del diablo, porque decían que se metía en todas las cosas [...] (Suárez, 2001: 314-315).

Sin embargo, existen narraciones que introducen modificaciones más relevantes. Así, en zonas como Lourizán (Pontevedra), el Urco adopta la forma de una ternera que se hace acompañar, al igual que en su versión más generalizada, de varios perros que la siguen en su deambular, aullando y ladrando. En este caso, la forma en la que anuncia la muerte es a través de tres grandes voces emanadas por el bóvido:

[...] ¿E usté como non dorme miña abuela? Aínda ei de sentir pasar a compaña. ¿A compaña? [...] ¿E que é iso miña abuela? Pois mira, mira chámanlle a compaña pero non é iso miña filla, non son xente morta, nin é... É o urco, e debe ser como unha becerra e dan tres voces e dispois leva os cans a ladrar, a tras da becerra, os cans a ladrar. ¡Chame por min que o quero mirar! Pois cala que cando o sinta ei de chamar. E efectivamente, chamaba por min, desperta miña filla, e sentía, non sentía os tres berros, pero sentía o último ¿entendes?, berraba tres veces como si fora unha vaca, pero moi grande. E dipois eu queríame levantar e mirar a ventana. ¡Hai, non te levantes da cama, non vaias mirar! E eu tamén sentía, e dispois levaba aquel rebaño de cans a ladrar, a ladrar. Ela disque logo dicía que a compaña pero que non era xente, que non era xente, que eran cans co ese animal, solo que claro que te acostumbras, que el era grande como si fora un becerro daba aquelas voces (Becoña, 1980: 137-138) .

\footnotetext{
${ }^{2}$ «¡No era por mí, hombre, no era por mí! Pero no era por ti ¿el qué? El perro que aullaba, hombre; había un perro aullando aquí había la mar de días y yo como tenía infección creía que aullaba porque iba a morir yo. Pero ha sido Antonio el que ha muerto esta noche [...] Eso del perro se lleva hoy en día aquí».

${ }^{3}$ «[...] ¿Y usted cómo no duerme abuela? Aún he de sentir pasar a la Compaña. ¿A la Compaña? [...] ¿Y qué es eso abuela? Pues mira, mira le llaman la Compaña pero no es eso hija mía, no son gente muerta, ni es... Es el Urco, y debe ser como una ternera y da tres voces y después lleva los perros ladrando, detrás de la ternera, los perros ladrando. ¡Llame por mí que lo quiero ver! Pues calla que cuando lo sienta te voy a llamar. Y efectivamente, me llamaba, despierta hija mía, y sentía, no sentía los tres gritos, pero sentía el último ¿entiendes?, gritaba tres veces como si fuera una vaca, pero muy grande. Y después yo me quería levantar y mirar por la ventana. ¡Ay, no te levantes de la cama, no vayas a mirar! Y yo también sentía, y después llevaba aquel rebaño de perros ladrando, ladrando. Ella al parecer decía entonces que la Compaña pero que no era gente, que no era gente que eran perros con ese animal, sólo que claro que te acostumbras, que él era grande como si fuera un ternero daba aquellas voces».
} 
La presencia de una ternera en sustitución del perro puede responder al registro de una antigua costumbre funeraria que perviviría a través de este singular sincretismo: la de presidir las marchas fúnebres con ciertos alimentos que, en casas de prestigio y opulencia, adquiría forma de ternera. En este sentido, Cabal afirmaba en sus investigaciones que «el llevar la ternera como oblada, fue antaño cosa corriente en las gentes de fortuna» (Cabal, 1925: 77). De este modo, al igual que otras tradiciones como los carros que venían recoger los vecinos fallecidos de determinadas parroquias dieron lugar a nuevas tradiciones en las que el sonido de un carro o su visión eran entendidos como el presagio de la muerte de una persona; en el caso de la ternera resulta factible que un componente de las obladas realizadas en el pasado acabara integrándose en una tradición popular vinculada igualmente con el imaginario de la muerte, como es el Urco.

Si continuamos explorando las variantes del Urco, en zonas como Viveiro (Lugo) esta creación carece de forma física y anuncia la muerte a través de ladridos que se escuchan desde el mar (véase Álvarez, 2004: 60).

En otros casos, su carácter marítimo se pierde, al igual que su denominación, pero su función y características se mantienen. Así, se puede englobar bajo el concepto de Urco seres como la Peregrina o Cadela das tetas largas, así como la Raposa do Morrazo y sus múltiples denominaciones: Raposa, Raposiña, Raposa facheira, Raposa do aire, Raposa de Morás, Raposa das mordazas, Raposa de morillas, Raposa dos morganzos o Zorra que canta como un gallo.

Con respecto a la Peregrina o Cadela das tetas largas, se trata de una figura documentada en las comarcas lucenses de A Mariña y A Terra Chá. Un relato recogido por Mariño la define como «un animal parecido a un perro que sale del cementerio para anunciar la muerte» (Mariño, 1995: 23). En realidad, consistiría en un alma en pena en forma de perra blanca (a veces también de una gata de análogo color) de diferentes tamaños que, en la versión de la Cadela das tetas largas, adquiriría unas grandes dimensiones, incluyendo unas ubres que arrastraría por el suelo, de ahí su denominación. En ningún caso se debe mirar a sus brillantes ojos ni tampoco golpearla, ya que puede atacar a quien lo haga. Más allá de estos detalles, sus atributos y acciones serían idénticos a los del Urco convencional, pero, en lugar del mar, saldría del cementerio parroquial, debido a que su localización se encuentra en áreas más del interior (véase Lisón, 1983: 400).

La Raposa do Morrazo, en cambio, presenta un escenario más amplio, abarcando zonas costeras, como la comarca de $\mathrm{O}$ Morrazo (Pontevedra) o el área de Padrón (A Coruña), pero también del interior, como los entornos de A Gudiña (Ourense) o Mondariz (Pontevedra) (véase Fraguas, 1973: 92). Al igual que sucedía con la Peregrina, se considera que, en realidad, esta Raposa es un alma errática en forma de zorra que emite gritos y aullidos estremecedores por las zonas frecuentadas por aquella persona cuya muerte es inminente. Asimismo, atentar o faltar a esta criatura, tanto en su versión visible como en la invisible (Raposa do aire), implicaría consecuencias muy negativas para el infractor que, en este caso, se traducen en la contemplación o recepción de las temibles llamaradas que emite la Raposa a través de su boca y sus ojos.

Si bien en el caso de la ternera podíamos intuir una vinculación de la apariencia del Urco con elementos asociados a costumbres funerarias pretéritas, en el caso de la Raposa, su materialización física parece responder a un sentido diferente. Tanto en la tradición gallega como en la asturiana, el zorro, y más aún, la zorra, se identifica con un componente maligno y traicionero que relaciona estrechamente al animal con el diablo y con otros personajes asimilados por este. En este sentido, hemos de tener en cuenta que el cristianismo desde su llegada y expansión por el noroeste peninsular asimiló con 
relativo éxito las divinidades situadas en los ámbitos celestes o «superiores», a través de mediadores como las vírgenes o los santos, pero no tanto las relativas al inframundo y al ámbito de la muerte (véase Freán, 2014). En estos espacios simbólicos, el cristianismo optó por engrosar sus límites y maldecirlos por medio de la figura de los demonios, encargados de revestir creencias y rituales de un mundo considerado pagano, como es el propio de todo aquello que escapa del dogma cristiano.

Aun así, tanto en el caso de la Peregrina como en el de la Raposa, siguen presentes aspectos que caracterizaban a la figura del Urco y que son los que permiten establecer vínculos entre ellas. De esta forma, en sus relatos siguen irrumpiendo las señales acústicas y visuales que presagian la inminencia de un fallecimiento. De igual modo, permanece el protagonismo de un ser que actúa con nocturnidad y, que, por ello, se asocia con el ámbito de la muerte. Finalmente, estamos ante criaturas que, al igual que el Urco, pertenecen y proceden del Más Allá y que, en esa condición, acceden al mundo de los vivos para reclamar aquello que va a formar parte de sus dominios. La diferencia radica en ese Borrón que se situaba en el interior del océano y que es trasladado en estas variantes a los cementerios, es decir, a las necrópolis («ciudad de los muertos») parroquiales, como consecuencia de situarnos en territorios del interior.

Hasta aquí el análisis de la tradición vinculada al Urco y sus variantes. Sin embargo, para lograr el objetivo de realizar un estudio completo de su figura, es necesario aludir también a otras creaciones que, por confusión, analogía o proximidad fonética, pueden asociarse erróneamente con Urco.

\section{OTRAS REPRESENTACIONES DEL URCO}

Siguiendo con esa asimilación del Urco con el diablo cristiano y, por lo tanto, con sus atributos, funciones y prácticas asociadas, el Urco también experimenta alteraciones que van más allá de su morfología y que afectan a su función y significado. Así, en ciertas tradiciones, el Urco se caracteriza por desempeñar acciones inofensivas, aunque molestas, propias de figuras similares a los trasnos y en donde adquiere manifestaciones físicas aleatorias, al igual que estos últimos: «[...] El Urco hacía cabronadas, temblar la tierra y se transformaba en perro, vaca, cabra, y hacía malas pasadas» (Llinares, 1990: 109).

De igual modo, se constatan versiones que dotan al Urco de un componente violento y destructivo, al definirlo como una especie de monstruo que atacaría a barcos y personas, como resultado, tal vez, de una asociación exacta con la propia muerte o la desgracia, en general. Asimismo, se tiene señalado que las personas que se cruzan con el Urco pierden el habla y entran en un estado de apatía depresiva que únicamente se puede erradicar mediante exorcismos o plegarias a santos como san Lorenzo. De este último se han constatado creencias como la contenida en este artículo de prensa del año 1938: «[...] La noche de San Lorenzo desarma los canes del Urco, que rondan los arenales desiertos y enciende todas las luminarias siderales [...]» (Anónimo, 1938).

En las localidades situadas en las proximidades de las montañas que dividen las actuales provincias de León y Asturias existen tradiciones en las que, ya no se habla de Urco, sino de Urca y en donde su función se desvincula del ámbito de la muerte, presentándose únicamente como una especie de lobo que ataca a los rebaños de la región:

Cuando yo tenía unos once años fui varias veces de zagal —una especie de pastor adjunto- con Pedro «Tumboilo», un vecino de origen asturiano que ocupaba la plaza de cabrero de mi barrio. Y Pedro «Tumboilo», amigo de contar a los rapaces muy fantásticas cosas, me habló muchas veces de una cueva en la que se hallaban enterrados los huesos de 
la urca —él decía «la urca», no «el urco»-, especie de lobo descomunal que en tiempos de Mari-Castaña acababa con todos los rebaños (Rabanal, 1962).

Sin embargo, el Urco que con mayor presencia y reconocimiento prevalece en la actualidad es el resultado de la innovación que un grupo de estudiantes creó en Pontevedra en el año 1876 con motivo de la celebración de sus carnavales. Como evidencia Farafullán en el inicio de la breve compilación Reinado y muerte del Urco. Colección de los documentos en prosa y verso publicados durante el carnaval de 1876 en Pontevedra, el Urco que Andrés Murais, Federico Guisasola, Piñeiro y Demetrio Durán popularizaron hasta el día de hoy en la ciudad del Lérez se aleja totalmente de la criatura que hemos caracterizado anteriormente:

El día 15 de febrero, corrió muy válido el rumor de que el Urco se hallaba en Pontevedra, y fueron de oír diferentes juicios que acerca de su existencia se emitían. Aseguraban unos que era el Urco un feroz animal capaz de tragarse de un solo mordisco veinte sacos de calderilla, con la misma facilidad que un burro traga dos granos de cebada; y ya que de burro hablo, diré que el Urco fue considerado también como uno mayor que la burra de Balaam, y que hablaba como ella, no faltando también quien jurara que el Urco era un animal de forma extraña en la cual se había alojado el alma en pena de no sé que importante personaje, viajando por lo tanto dicha alma de incógnito, si se me permite la frase, y cometiendo mil calaveradas. Vox populi, vox Dei, acostúmbrase a decir. ¡Falsa máxima que envuelve el más crasísimo de los errores! El Urco no había entrado en Pontevedra y lejos de ser lo que se atribuía, era un poderosísimo rey, que desde remotas tierras y acompañado de su corte y ejército venía a visitar el país de Helenes.

De este modo, el nuevo Urco se revestía de un tono clásico y grecorromano, muy alejado de su homónimo tradicional en apariencia, atributos, acciones e, incluso, compañía, al sustituir el séquito de perros por figuras como Teucro, Minerva, Ceres o Neptuno. Con todo, la analogía lógica entre lo que se estaba creando en Pontevedra y lo que existía en el imaginario popular de sus gentes no pudo evitar que en las celebraciones de este primer carnaval de 1876 se reviviera en algún momento la figura legendaria del Urco original. Así lo atestigua este precioso romance cantado y vendido por un ciego, su mujer y su criado en el baile de máscaras del Liceo Casino ${ }^{4}$.

\section{Primera PARTe}

Mucha atención caballeros

Que a contar voy un suceso

Piramidal, monstruoso,

Y que eriza los cabellos.

Duendes, trasgos y fantasmas,

Brujas, compañas y muertos,

Almas que vagáis errantes,

Espíritus del Averno,

Yo os invoco a todos juntos
Para que inspiréis mi estro

Y pueda salir airoso

Del lance que hoy acometo.

La nerviosa damisela

Y el pollo sensibilero

Harán bien en retirarse

Pues que pueden quedar tiesos

Al oír el caso raro,

Que sucede en este pueblo.

$\mathrm{Y}$ es muy fácil que después

Tengan pesados ensueños,

\footnotetext{
${ }^{4}$ Romance recogido en la compilación Reinado y muerte del Urco. Colección de los documentos en prosa y verso publicados durante el carnaval de 1876 en Pontevedra del año $1876 \mathrm{y}$, posteriormente, en el artículo «Hace hoy cuarenta años...», El Diario de Pontevedra: periódico liberal, 3 de marzo de 1916.
} 
Y alboroten los vecinos

Al oír que ladra un perro.

Sólo los hombres de pró

Es decir, de pelo en pecho

Y las mujeres de arranque

Y las niñas... coraceros

Podrán oír este caso

Tan curioso y verdadero;

Conque afilar las orejas

Y escuchar que ya comienzo.

Después que la una da

En los relojes del pueblo

-Digo, luego que da en uno

Y que la canta el sereno,

Pues los dos jamás la dan

Ni la marcan nunca a tiempo,

Que diferencias políticas

Los tienen siempre de cuerno

Y si uno avanza hasta el rojo

Otro retrocede al neo.-

Pues bien a la hora dicha

Cuando todo está en silencio

$\mathrm{Y}$ tan solo de los gatos

Se oyen los arrullos tiernos

Y las quejas amorosas

Y los rabiosos requiebros;

Es fama que de la mar,

Sale un animal horrendo

Que no está clasificado

$\mathrm{Y}$ que se parece a un perro

Aunque en tamaño mayor

Pues escede al de un jumento,

Y perdónenme este modo

De comparar que yo tengo;

El que dando un resoplido

Y sacudiéndose el pelo,

Hace resonar las cadenas

Que le rodean el cuerpo

Y emprende por la ciudad

Su misterioso paseo.

Siguen a este horrible ser

Formando su digno sequito

Otros muchos animales

Pero que son más pequeños

Y en cerrado pelotón

Dando aullidos agoreros

Recorren plazas y calles

Sembrando el pavor y el miedo;

Y aquí concluye esta parte

Pues se me estremece el cuerpo
Tan solo con recordar

Lo que aun que contar tengo,

Y que el curioso lector

Por una pieza del perro

Comprándome este romance

Sabrá con puntas y pelos,

Pues en la segunda parte

Está lo mejor del cuento.

\section{Segunda Parte}

Cierta noche a la una dada

De este crudísimo invierno

Pues anunciaba el termómetro

Siete grados bajo cero;

En el quicio de una puerta

Meditaba así un sereno:

"iQue tormenta nos amaja,

Que noche, váljame el sielo,

Este farol se me apaja

Y está chuviscando helo

Si esto contínua así

Me voy a quedar más tieso

Que el chuzo municipal

Que empuño a guisa de cetro».

Así discurría el mísero

Transido de frio y sueño,

Cuando un ruido sintió

Que le 1lenó de canguelo,

$\mathrm{Y}$ un quejido sepulcral

Que triste repite el eco,

$\mathrm{Y}$ al que contestan a coro

Cien aullidos diversos;

Ya se encomendaba a Dios,

Pues era tanto su miedo

Que de la cabeza iba

Escapándole el sombrero,

Cuando a muy poca distancia

Descubre un bulto muy negro,

$\mathrm{Al}$ que siguen otros bultos

Que a él se le figuran perros,

$\mathrm{Y}$ a un enlutado fantasma

Presidiendo este cortejo.

Viendo que la cosa avanza,

Atribulado el sereno

Le da sebo a los zancajos,

Toma las de Villadiego

Y corre desalentado

En velocísimo vértigo

Hasta que todo mohino

Da en la cama con su cuerpo.

Los vecinos de la calle 
Donde pasó este suceso

Diz que aquella noche en cama

Los aullidos sintieron,

$\mathrm{Y}$ aún algunos atrevidos

Las cortinas descubriendo

Vieron... pero no lo digo

Que la cosa es un misterio

Y aclararlo no conviene

Pues ya lo aclarará el tiempo.

Entre tanto no temáis

Al Urco ni a sus excesos

Y en alegres carcajadas

Pasemos aqueste invierno,
$\mathrm{Y}$ troquemos este frio

Que nos traspasa los huesos,

En piruetas y en cabriolas

Sin que nos turbe el recuerdo

De la sentencia fatídica

De aquellos facciosos versos (I)

Que a todos nos amenazan

Con ir saltando al infierno:

$\mathrm{Y}$ aquí termina el romance

Aunque no concluye el cuento.

(I) Muchacha que vas bailando

$\mathrm{Al}$ infierno vas saltando.

Con todo, el Urco no solo se vio afectado por la invención de nuevas tradiciones que alteraban su significado y sentido original. La globalización del imaginario popular, unido al olvido y el desconocimiento del propio, hicieron que el Urco, a mediados de los años 50, llegara a ser confundido en la localidad de Rianxo (A Coruña) con una especie de «yeti»:

[...] No hay duda, en cambio, en cuanto a las huellas del «urco». Las ha dejado bien claras en «la calle del medio» de Rianxo. [...] Hará dos años, por estos días, que apareció el «urco» en el muelle de Rianxo. Lo vieron algunas mujeres que esperaban la vuelta de las dornas. Quienes contemplan al «urco», quedan paralizados por el estupor; son incapaces de gritar y de correr. El «urco» aparece en forma de perro pequeño, de aguas sin duda, y al pisar la tierra va agrandándose, hinchándose, hasta el tamaño de un caballo o de un buey. El «urco» aquella noche se dirigió a la «calle del medio» donde el cemento echado aquella misma tarde, estaba fresco. Al sentir que se hundía retrocedió pero dejó bien claras sus huellas. Eran las de un animal que andaba a dos patas. Y es que el «yeti» es un bicho de fácil adaptación a todos los ambientes; por los ventisqueros helados se desliza sobre las posaderas; al acercarse a los puertos nada como un perro; quizá más lejos de la costa nade como un delfin; y, naturalmente, por las calles urbanizadas anda como un hombre hecho y derecho. A la mañana siguiente los vecinos de Rianxo se quedan asombrados al advertir las huellas del «urco». [...] Aquellas huellas impresas en la «calle del medio» de Rianxo durante una noche primaveral sólo podían ser las del «urco», nuestro «yeti», nuestro abominable «hombre de las playas». La lástima es que de tanto pasar gente por «la calle del medio», se desgastó el cemento y ya apenas se observan las huellas del «urco» (Borobó, 1954).

\section{SigNIFICAdO E INTERPRETACIÓN DEL URCO EN GALICIA Y AstURIAS}

Si volvemos a la figura original del Urco y dejamos de lado las distorsiones de los «falsos Urcos» expuestos anteriormente, son varias las interpretaciones que se han señalado sobre su origen y significado. Así, muchos autores sostienen que el Urco representa una muestra de la pervivencia de antiguas creencias prerromanas vinculadas con dioses como Vestio Alonieco, divinidad cornuda cuyo culto se ha constatado en la localidad pontevedresa de Lourizán y que cuenta con una posible asociación con un bajorrelieve que reproduce una efigie dotada de cuernos (véase Anónimo, 1965).

Pero, sin duda, de entre las interpretaciones que basan sus hipótesis en analogías con creencias constatadas en otras cronologías y espacios geográficos, la más extendida 
es aquella que sitúa al Urco como un recuerdo o evolución del can Cerbero grecorromano. Esta teoría se apoya en la comparación de los atributos y acciones del Urco con las propias de un perro mítico que habita en el inframundo con la función de proteger al mundo de los muertos de la entrada de cualquier ser vivo, así como de la salida de los muertos del mismo y de atemorizar, junto a las Furias, a las sombras que veían en su ira la primera muestra de los múltiples castigos que recibirían en el Tártaro. Además, a esta interpretación se sumaría la analogía fonética existente entre Urco y la divinidad latina Orcus que, posteriormente, pasó a denominar al conjunto del espacio destinado al ámbito de los muertos.

A partir de este posible origen y significado, Filgueira Valverde (1977: 56-57) argumentaba que el Urco podría constituir también una forma de denominar al mundo de los muertos y, por ello, todo lo relacionado o perteneciente con él, incluida la propia muerte o su premonición. Esta misma interpretación era la que señalaba años atrás Cabal:

El Urco. Parece, pues, que en tiempos antañones se debió de llamar «huerco» todo lo que llegaba hasta nosotros como aviso de la tumba. Huerco, la sombra del futuro muerto; huerco, el ataúd en el que se metía; huerco, el perro que aullaba por la noche... Y huerco, indudablemente, todo animal agorero de igual significación (Cabal, 1925: 55-56).

Otros análisis han ido encaminados al estudio de su etimología. En este sentido, se han apuntado hipótesis que establecen una vinculación del término Urco con el derivado del sánscrito «urka-s», es decir, «lobo» (véase Rabanal, 1962), un animal estrechamente asociado con la muerte en las culturas indoeuropeas.

Desde nuestro punto de vista y sin rechazar ninguna de las propuestas enunciadas, consideramos necesario analizar primero el contexto en el que se desarrolla la creación del Urco para después recurrir a esas analogías tan recomendables para ofrecer perspectivas alternativas que permitan enriquecer la formulación de nuevas interpretaciones.

Si bien es cierto que la presencia de figuras semejantes al Urco se pueden encontrar en gran parte de Europa y de América (véase Pedrosa, 2017), e incluso en buena parte de las mitologías antiguas, el Urco gallego posee la singularidad de ser una entidad autónoma que no responde ante los mandatos de ninguna divinidad o ente superior, que reside, por lo tanto, en un reino propio y que se traslada al mundo de los vivos para reclamar las almas de aquellos que pasarán a formar parte de sus dominios.

Pero, tal vez, lo más singular de esta creación con respecto a otras figuras similares es que, por el contexto de creencias en el que se envuelve, habita en un espacio socialmente reconocido como sagrado y, por lo tanto, no asimilable con la figura del diablo cristiano. Así, según las creencias gallegas, «el demonio no puede entrar en el mar porque éste es sagrado» (Llinares, 1990: 106), por lo que, si los demonios no pueden entrar, el Urco no puede ser un demonio, ya que, además, habita en él. Pero, si el demonio tiene incapacitada su entrada en el mar, figuras cristianas como los curas tampoco son bienvenidos dentro de este ámbito: «es mal agüero ver a curas o mujeres al salir del mar; más aún, al sacerdote ni siquiera se le puede nombrar en el mar, es tabú esa palabra» (Lisón, 1983: 390).

En este sentido, consideramos que los orígenes del Urco deben buscarse en las creencias vigentes en el territorio con anterioridad a la irrupción del cristianismo. De este modo, por su carácter soberano y marítimo, es posible que detrás del Urco se esconda el recuerdo de alguna divinidad que regiría un mundo de los muertos entendido en clave oceánica. En él, las corrientes acuáticas cobrarían especial relevancia como elemento de tránsito a un más allá situado en las profundidades del mar y del océano, pero también 
la comunidad humana entendida como la unión de vivos y muertos simbolizada en las actuales unidades parroquiales.

A raíz de las investigaciones más recientes sobre religiosidad prerromana y romana del noroeste peninsular (véase Freán, 2019), la analogía más próxima a la caracterización señalada para Urco se podría establecer con las divinidades prerromanas Reve y Nabia. La primera presenta una naturaleza soberana asociada a elementos de acceso o tránsito al mundo de los muertos, mientras que la segunda desempeñaría una función psicopompa a través de medios acuáticos. Ahora bien, con esta hipótesis no pretendemos afirmar que Urco constituya una transposición directa de los supuestos rasgos de estas divinidades prerromanas o una síntesis de ambas, sino un eventual recuerdo de un imaginario de la muerte dotado de características y elementos muy diferentes a los difundidos, primero, por las creencias romanas y, posteriormente, por las cristianas. Un recuerdo que, en definitiva, fue incorporando alegorías y representaciones acordes a la evolución de la mentalidad que experimentaron los portadores de su tradición y su adaptación a los nuevos contextos religiosos y culturales a los que fueron expuestos.

\section{Conclusiones}

El análisis del Urco gallego, como cualquier otra manifestación de la cultura popular de tradición oral, evidencia una riqueza cognitiva que, aunque pueda parecer extraña y lejana en la actualidad, resulta de gran ayuda para interpretar los mecanismos que integran el funcionamiento de nuestra sociedad a todos los niveles (social, económico, ideológico, religioso, cultural) y, por supuesto, la que un día dio sentido a su existencia y recreó sus relatos para comprender mejor el mundo en el que vivía.

De este modo, la figura del Urco nos ilumina sobre las creencias y las mentalidades que conformaban el concepto de muerte y la forma de afrontarla desde momentos anteriores a la cristianización de su territorio hasta épocas muy recientes en las que sus relatos se reproducían, precisamente, porque servían para explicar una determinada realidad que, en cierta medida, y a pesar de las modificaciones que se han vivido en las últimas décadas, continúa vigente: la idea de que la muerte es predecible, la relación de la muerte con la noche, la interacción entre el mundo de los muertos y el de los vivos, la relevancia de la parroquia para sancionar sus límites o la importancia del agua en el tránsito al más allá.

\section{BibliografíA}

Álvarez Peña, Alberto (2004): Mitología gallega, Gijón, Picu Urriellu.

ANÓNImo (1876): Reinado y muerte del Urco. Colección de los documentos en prosa y verso publicados durante el carnaval de 1876 en Pontevedra, Pontevedra: Imprenta de Verea y Quintáns.

Anónimo: «Hace hoy cuarenta años...», El Diario de Pontevedra: periódico liberal, 3 de Marzo de 1916.

Anónimo: «Historia y leyendas de Pontevedra», La Noche: único diario de la tarde en Galicia, 9 de Agosto de 1965.

ANÓnimo: «Modo y milagro de SAn Lorenzo», El Pueblo gallego: rotativo de la mañana, 10 de Agosto de 1938.

Becoña Iglesias, Elisardo (1980): La Santa Compaña, el Urco y los muertos, A Coruña, Magoygo. 
Borobó: «LAS hUEllas Del URCO», La Noche: único diario de la tarde en Galicia, 21 de abril de 1954.

CABal, Constantino (1925): La mitología asturiana. Los dioses de la muerte, Madrid, Imprenta de Juan Pueyo.

Castro, Antón (2007): «Urco, el perro del mar», Sens Public, 6, pp. 1-8.

Cuba, Xoán Ramiro, Reigosa, Antonio y Miranda, Xosé (2006): Dicionario dos seres míticos galegos, Vigo, Xerais.

Fernández Insuela, Antonio (1993): «Cuentos de la tradición oral de Orense», Boletín Auriense, 23, pp. 149-195.

Filgueira Valverde, José (1977): «Del Urco al esperpento», Revista de Dialectología y Tradiciones Poulares, 33, pp. 55-60.

Fraguas Fraguas, Antón (1973): La Galicia insólita. Tradiciones gallegas, A Coruña, Edicións do Castro.

Freán CAMPo, Aitor (2014): «Persistencia en la tradición cultural del noroeste peninsular: una exploración del imaginario de la muerte hacia el pasado», Gallaecia, 33, pp. 159-188.

FreÁn CAMPo, Aitor (2019): Religiones y mentalidades del noroeste peninsular. De la Edad del Hierro a la Tardoantigüedad, Málaga, Seleer.

Lisón Tolosana, Carmelo (1983): Brujería, estructura social y simbolismo en Galicia. Antropología cultural de Galicia. 2, Madrid, Akal.

Lisón Tolosana, Carmelo (1998): La Santa Compaña. Fantasías reales. Realidades fantásticas, Madrid, Akal.

Llinares García, María del Mar (1990): Mouros, ánimas, demonios, Madrid, Akal.

LoIs, Octavio (1887): «Apuntes para el Folk-lore gallego. El Urco», Galicia: revista regional, 2, pp. 97-101.

Mariño Ferro, Xosé Ramón (1995): Aparicións e Santa Compaña, Vigo, Edicións do Cumio.

Pedrosa, José Manuel (2017): «Los perros de Dios y los perros del diablo», en Del inframundo al ámbito celestial: Entidades sobrenaturales de la literatura tradicional hispanoamericana, Carranza Vera y Rocha Valverde (coords.), San Luis Potosí, El Colegio de San Luis, pp. 113-137.

Rabanal, Manuel: «El Urco y la Urca», La Noche: único diario de la tarde en Galicia, 24 de noviembre de 1962.

SuÁrez López, Jesús (2001): Tesoros, ayalgas y chalgueiros. La fiebre del oro en Asturias, Gijón, Fundación Municipal de Cultura, Educación y Universidad Popular.

Fecha de recepción: 25 de septiembre de 2019

Fecha de aceptación: 12 de diciembre de 2019

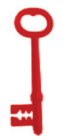

